\title{
Enthesopathy and the Cutaneous Disease Activities in Psoriatic Arthritis
}

\author{
Mohieldin M Ahmed $^{1^{\star}}$, Naglaa M Sayed ${ }^{2}$, Aziz K Alfeeli $^{1}$, Ayyoub B Baqer ${ }^{3}$ \\ ${ }^{1}$ Physical Medicine and Rehabilitation Department, Amiri Hospital, Ministry of Health, Kuwait; ${ }^{2}$ Dermatology Department, \\ Amiri Hospital, Ministry of Health, Kuwait; ${ }^{3}$ Physical Medicine and Rehabilitation Department, Al-Farwania Hospital, Ministry \\ of Health, Kuwait
}

Citation: Ahmed MM, Sayed NM, Alfeeli AK, Baqer
AB. Enthesopathy and the Cutaneous Disease
Activities in Psoriatic Arthritis. Maced J Med Sci.
$2013 \quad$ June $\quad$ 15; 2 ; $162-167$.
http://dx.doi.org/10.3889/MJMS.1857-5773.2013.0276.
Key words: Psoriatic arthritis (PsA); enthesopathy;
Leeds Enthesitis Index (LEI); CRP and Psoriasis
Area and Severity Index (PASI).
"Correspondence: Dr. Mohieldin M. Ahmed, MD.
Head of Physical Medicine and Rehabilitation
department, Amiri Hospital, Ministry of Health,
Kuwait. Phone: +96566542343.
drmohyahmed@yahoo.com E-mail:
Received: 18-Nov-2012; Revised: 21-Jan-2013;
Accepted: 24-Jan-2013; Online first: 15-Apr-2013
Copyright: @ 2013 Ahmed MM. This is an open-
access article distributed under the terms of the
Creative Commons Attribution License, which
permits unrestricted use, distribution, and
reproduction in any medium, provided the original
author and source are credited.
Competing Interests: The authors have declared Competing Interests: The author
that no competing interests exist.

\begin{abstract}
Aim: To investigate entheseal abnormalities by using Leeds Enthesitis Index (LEI) score in Psoriatic arthritis (PSA). Also, to find the correlation of LEI score and parameters of the activities of the cutaneous disease at baseline and after 6 months of treatment in PsA. Furthermore, to find correlation between LEI score and C-reactive protein (CRP) and Psoriasis Area and
\end{abstract} Severity Index (PASI) score as well as acute phase reactants.

Materials and Methods: A total of thirty-nine patients with PsA and thirty-five age and sex matched healthy subjects were recruited. Clinical and laboratory assessment of disease activity included LEI score, PASI score, erythrocyte sedimentation rate (ESR) and CRP and were measured at baseline and after 6 months of treatment.

Results: Enthesopathy showed a significant prevalence among PsA of 20.5\%. We found a highly significant decreased in LEI score, PASI score, ESR and CRP at baseline compared to results after 6 months of treatment in PSA. A significant correlation between PASI score and LEI score was found. Also, PASI score was significant correlated with ESR and CRP in PsA.

Conclusion: Enthesopathy showed a significant prevalence among PSA. The good potential parameters for PSA were LEI score, PASI score, ESR and CRP in PSA. Also, they may be the predictive value of changes induced by biological treatment in PsA.

\section{Introduction}

Enthesis is defined as the site of insertion of a tendon, ligament, fascia, or articular capsule into bone. Pain originating in the free nerve endings enriched entheses (enthesalgia) may represent a potential cause of chronic musculoskeletal pain in some individuals [1]. Enthesitis is inflammation at the bony insertion of tendon, ligament, or joint capsule. It is common in PsA and considered important by affected patients and It may be associated with a more severe psoriasis outcome [2].

PsA is an inflammatory arthropathy associated with skin psoriasis [3]. It encompasses several subgroups where in the common denominator is an association with skin psoriasis. The spectrum of joint inflammation in PSA is great, ranging from axial to peripheral disease, synovial and adjacent soft tissue inflammation, enthesitis, osteitis, new bone formation and severe osteolysis, and overlaps of all of these [4]. PsA pathophysiology is centered on the enthesis organ. A hypothesis in PsA is that enthesitis arises at sites of high shear and compression forces, with the additive interaction between mechanical stress, microtrauma, and tissue repair mechanisms, and bacterial molecules variably leading to inflammation [5].

Enthesitis is a common feature in PSA. Instruments quantifying enthesitis have been developed in PsA called Leeds Enthesitis Index (LEI) which consists of 6 sites: both lateral epicondyles, both medial epicondyles, and both Achilles tendon insertions [6]. Other measures were to assess active inflammation in peripheral joints in PsA including increased concentrations of acute phase reactants (e.g. erythrocyte sedimentation rate [ESR], C-reactive protein [CRP]) which observed in patients with PsA [7, 
8]. Moreover, elevations in acute phase reactants are associated with a poorer outcome in PsA [9].

A widely used instrument of activity in the skin is the psoriasis area and severity index (PASI). The PASI assesses individual psoriatic lesions for erythema, thickness/induration, and scale, and then uses a formula to account for the overall extent of the body surface area of skin involved with scores ranging from 0-72 [10].

Thus, the aim of the present study was to investigate the presence of entheseal abnormalities by using the LEI in PSA. Also, to find the correlation of LEI and parameters of the activities of the cutaneous disease at baseline and after 6 months of treatment in patients with PSA. Furthermore, to find correlation to the activities of the cutaneous disease as reflected by the PASI score and acute phase reactants such as ESR and CRP.

\section{Subjects and Methods}

A total of thirty-nine patients with moderate-tosevere psoriatic arthritis (20 males and 19 females and age of $32.8 \pm 6.69$ years) were recruited form outpatient clinics, physical medicine and dermatology departments together with thirty-five age and sex matched healthy subjects as a control group. Patients underwent treatment with DMARD and biologic agents [etanercept (Enbrel ${ }^{\circledR}$ ) and adalimumab (Humira $\AA$ )] . Patients underwent treatment with biological agents if they were unresponsive to or had contraindications for at least two other conventional systemic treatments (methotexate, leflunomide, sulphasalazine). Diagnostic criteria necessary to establish a case of psoriatic arthritis vary, but all require evidence of skin disease and an inflammatory arthritis [11]. Also, clinical diagnosis was made using CASPAR (CIASsification criteria for Psoriatic ARthritis) criteria for PsA [12].

Inclusion criteria for cases were age more 18 years; diagnosis of chronic plaque psoriasis; presence of any clinical signs and symptoms of articular involvement (including axial and peripheral involvement); presence of clinical signs and symptoms of enthesopathy (including Achilles, quadriceps, patellar and plantar aponeurosis enthesitis); presence of radiological signs of spinal hyperostosis and absence of any systemic treatment for psoriasis in the previous 3 months prior to clinical and ultrasound evaluation.

Exclusion criteria for cases were drug-induced tendinopathy e.g. Fluoroquinolones and Retinoid, rheumatoid nodules, rheumatoid arthritis, crystal induced arthritis, grade IV osteoarthritis, Reiter's syndrome, obvious inflammatory bowel disease, other active inflammatory skin conditions, metabolic and endocrine disorders, severe comorbidities, serious infection and tuberculosis infection.
Clinical and laboratory evaluations were performed at baseline and after 6 months of treatment. Clinical and laboratory assessment of disease activity included the following clinicolaboratory parameters: the Leeds Enthesitis Index (LEI) [6], Psoriasis Area and Severity Index (PASI) [10], a measure of acute-phase response (CRP and ESR). ESR was measured by the standard Westergren method $(\mathrm{mm} / \mathrm{h})$ [13]. CRP levels were measured by standard nephelometry (mg/L) [14]. Rheumatoid factor (RF) was measured by enzymelinked immunosorbent assay and results are expressed in titres of 1/40 and higher [15].

Measures of enthesitis included LEI score which consisted of bilaterally 6 sites: right and left Achilles tendon insertions, medial femoral condyles superior to the joint line, and lateral epicondyles of the humerus at the common extensor origin. The pressure was exerted at the enthesis sufficient to blanch the finger nail of the examiner (approximately $4 \mathrm{Kg}$ ). In addition, the examiner assessed the presence of softtissue swelling at the enthesis [6].

Measures of skin disease activity included psoriasis Area and Severity Index (PASI) which assesses individual psoriatic lesions for erythema, thickness/induration, and scale, and then uses a formula to account for the overall extent of the body surface area of skin involved, with scores ranging from 0-72. [10].

Patients underwent treatment with NSAIDs (92.3\% of 39 cases of PSA), DMARD (methotexate, $76.9 \%$ ) and biologic agents (anti-tumor necrosis factor, $28.2 \%$ ) and combined therapy (43.6 \%). Nonresponders to the following drugs, such as NSAIDs $(92.3 \%)$ and MARDs (methotexate, $76.9 \%)$ were not excluded, but those patients underwent treatment with biological agents or combined therapy if they were unresponsive to or had contraindications for at least two other conventional systemic treatments (methotexate). We measured LEI score, PASI score, laboratory parameters of acute phase response indices, including ESR and CRP at baseline and after 6 months of treatment in patients with PsA.

\section{Statistical analysis}

Study data were analyzed using the SPSS statistical package (SPSS, version 16.0) for data processing. Quantitative data were presented as mean ( $\pm S D)$. The Student's $t$ test indicates the magnitudes of the differences of means and SD between groups of patients and controls and therefore the magnitude of the observation. Prior to data analysis, the level of significance was established at $P<0.05$. Correlation between variables was done and Pearson correlation coefficient was calculated. All tests were 2-tailed and considered statistically significant at $\mathrm{p}<0.05$. 


\section{Results}

Table 1 summarizes demographic, clinical and laboratory findings in 39 patients with PsA and 35 control group at baseline. Of the 39 patients with PsA, the most frequently clinical findings of psoriatic arthritis were enthesopathy $(20.5 \%)$, oligoarthritis (53.8\%), polyarthritis $(25.5 \%)$, spondylitis $(12.8 \%)$ and DIP involvement $(7.71 \%)$. The most frequently clinical findings of psoriasis were generalized plaque (psoriasis vulgaris) (56.4\%), localized plaque (psoriasis vulgaris) (28.2 \%), guttate (guttate psoriasis) (12.8\%) and pustular (pustular psoriasis) $(2.6 \%)$. In addition, mean ( \pm SD) of LEI score was $5.1( \pm 0.7)$ and mean $( \pm$ SD) of PASI was $20.8( \pm 5.1)$. Also, there were no significant differences BMI between cases and controls. However, there were significant differences in ESR $(p<0.05)$ and CRP $(p<$ 0.05 ) between cases and controls.

Table 1: Demographic, clinical and laboratory findings at baseline in 39 patients with psoriatic arthritis and 35 control group.

\begin{tabular}{|c|c|c|c|}
\hline $\begin{array}{l}\text { Characteristics (the mean } \pm \\
\text { SD) }\end{array}$ & $\begin{array}{l}\text { Cases } \\
(\mathrm{N}=39)\end{array}$ & $\begin{array}{l}\text { Control } \\
(\mathrm{N}=35)\end{array}$ & $\begin{array}{c}\mathrm{p}- \\
\text { value }\end{array}$ \\
\hline Age (years) range & $32.8 \pm 6.69$ & $34.5 \pm 8.3$ & - \\
\hline Gender ( male /female) & $18 / 21$ & $17 / 18$ & - \\
\hline Disease duration (years) range & $9.3 \pm 4.8$ & - & - \\
\hline $\begin{array}{l}\mathrm{BMI}\left(\mathrm{kg} / \mathrm{m}^{2}\right) \\
\text { Medications, } \mathrm{n}(\%)\end{array}$ & $25.6 \pm 5.2$ & $27.7 \pm 3.3$ & $p>0.05$ \\
\hline $\begin{array}{l}\text { - NSAID } \\
\text { - Methotexate (7.5-17.5 }\end{array}$ & $36(92.3 \%)$ & - & - \\
\hline $\mathrm{mg} / \mathrm{week})$ & $30(76.9 \%)$ & - & - \\
\hline - Anti-tumor necrosis factor & $11(28.2 \%)$ & - & - \\
\hline $\begin{array}{l}\text { - Combined therapy } \\
\text { Clinical presentations of } \\
\text { arthritis, } \mathrm{n}(\%)\end{array}$ & $17(43.6 \%)$ & - & - \\
\hline - Low back pain & $13(33.3 \%)$ & - & - \\
\hline - Enthesopathy & $8(20.5 \%)$ & - & - \\
\hline - Oligoarthritis & $21(53.8 \%)$ & - & - \\
\hline - Polyarthritis & $10(25.5 \%)$ & - & - \\
\hline - Dactylitis & $7(17.9 \%)$ & - & - \\
\hline - Sacroiliitis & $2(5.1 \%)$ & - & - \\
\hline - Spondylosis & $5(12.8 \%)$ & - & - \\
\hline $\begin{array}{l}\text { - DIP involvement } \\
\text { Clinical Presentations of } \\
\text { Psoriasis, } n(\%)\end{array}$ & $3(7.7 \%)$ & - & - \\
\hline $\begin{array}{l}\text { - Itching } \\
\text { - generalized plaque }\end{array}$ & $33(84.6 \%)$ & - & - \\
\hline (psoriasis vulgaris) & $22(56.4 \%)$ & - & - \\
\hline - localized plaque & $11(28.2 \%)$ & - & - \\
\hline - Guttate (guttate psoriasis ) & $5(12.8 \%)$ & - & - \\
\hline - Pustular (pustular psoriasis) & $1(2.6 \%)$ & - & - \\
\hline Laboratory Findings : & & & \\
\hline - RF positive, n (\%) & All negative & - & - \\
\hline • ESR( mm/hour) & $40.3 \pm 9.5$ & $6 \pm 5.5$ & $\mathrm{p}<0.05$ \\
\hline $\begin{array}{l}\text { - C-reactive protein (mg/L) } \\
\text { Activity Index score : }\end{array}$ & $16.7 \pm 7.4$ & $3.6 \pm 2.2$ & $p<0.05$ \\
\hline - Leeds Enthesitis Index score & $5.1 \pm 0.7$ & - & - \\
\hline Index score & $20.8 \pm 5.1$ & - & - \\
\hline
\end{tabular}

Table 2 and Figures 1 and 2 summarizes mean $( \pm$ SD) of clinicolaboratory parameters of disease activities at baseline and after 6 months of treatment in 39 patients with PsA. After the satisfactory response of PSA to the following drugs such as NSAIDs, steroids, DMARDs and biological Agents, we observed a significantly improvement of LEI score, PASI score, ESR and CRP at baseline compared to results after 6 months of treatment in 39 patients with PsA.

Table 2: Correlations of clinicolaboratory parameters of disease activities at baseline and after 6 months of treatment in patients with psoriatic arthritis.

\begin{tabular}{lccc}
\hline Mean \pm SD (Range) & At baseline & 6 months & $\begin{array}{c}\mathrm{p}- \\
\text { value }\end{array}$ \\
\hline ESR (mm/hour) & $40.3 \pm 9.5$ & $26.5 \pm 6.2^{\star}$ & $\mathrm{p}<0.05$ \\
$\begin{array}{l}\text { C-reactive protein (CRP) } \\
\text { mg/liter }\end{array}$ & $16.7 \pm 7.4$ & $6.7 \pm 3.5^{*}$ & $\mathrm{p}<0.05$ \\
$\begin{array}{l}\text { Leeds Enthesitis Index (LEI) } \\
\text { Score }\end{array}$ & $5.1 \pm 0.7$ & $1.2 \pm 0.6^{\star *}$ & $\mathrm{p}<0.001$ \\
$\begin{array}{l}\text { Psoriasis Area and Severity } \\
\text { Index (PASI) score }\end{array}$ & $20.8 \pm 5.1$ & $6.4 \pm 1.3^{\star *}$ & $\mathrm{p}<0.001$ \\
\hline N.B. ${ }^{* \star} \mathrm{p}<0.0001=$ highly significant $;{ }^{*} \mathrm{p}<0.05=$ significant. & &
\end{tabular}

We found a highly significant decreased in mean ( \pm SD) of LEI score at baseline compared to results after 6 months of treatment (5.1 \pm 0.7 vs. $1.2 \pm$ $0.6, p<0.001)$ and a highly significant decreased in mean $( \pm S D)$ of PASI at baseline compared to results after 6 months of treatment $(20.8 \pm 5.1$ vs. $6.4 \pm 1.3$, p $<0.001)$. Also, there was a significant decreased in mean $( \pm \mathrm{SD}$ ) of ESR ( $\mathrm{mm} /$ hour) at baseline compared to results after 6 months of treatment $(40.3 \pm 9.5$ vs. 26. $5 \pm 6.2, p<0.05$ ) and a significant decreased in mean ( \pm SD) of CRP (mg/liter) at baseline compared to results after 6 months of treatment $(16.7 \pm 7.4 \mathrm{vs}$. $6.7 \pm 3.5, p<0.05)$ in 39 patients with PsA.

Table 3: Correlation between Psoriasis Area and Severity Index (PASI) score at bases and Leeds enthesitis index (LEI) score as well as some clinicolaboratory parameters of disease activity at baseline in patients with psoriatic arthritis.

\begin{tabular}{lc}
\hline Data & Psoriasis Area and Severity Index score \\
\hline Age & $r=0.144 ; p>0.05 \mathrm{NS}$ \\
Disease duration & $r=0.091 ; p>0.05 \mathrm{NS}$ \\
BMI $\left(\mathrm{kg} / \mathrm{m}^{2}\right)$ & $r=0.031 ; p>0.05 \mathrm{NS}$ \\
Leeds enthesitis index score & $r=0.538^{\star \star} ; p<0.001 \mathrm{HS}$ \\
ESR (mm/hour) & $r=0.271^{\star} ; p<0.05 \mathrm{~S}$ \\
C-reactive protein (mg/L) & $r=0.269^{*} ; p<0.05 \mathrm{~S}$ \\
\hline N.B. ${ }^{* \star} p<0.001=$ highly significant $;{ }^{*} p<0.05=$ significant $; p>0.05=$ non-significant.
\end{tabular}

Table 3 and Figure 3 present linear regression $(r-)$ correlation between mean $( \pm S D)$ of PASI score and LEI score as well as all clinicolaboratory parameters of disease activities including ESR, CRP at baseline in patients with PSA at baseline.

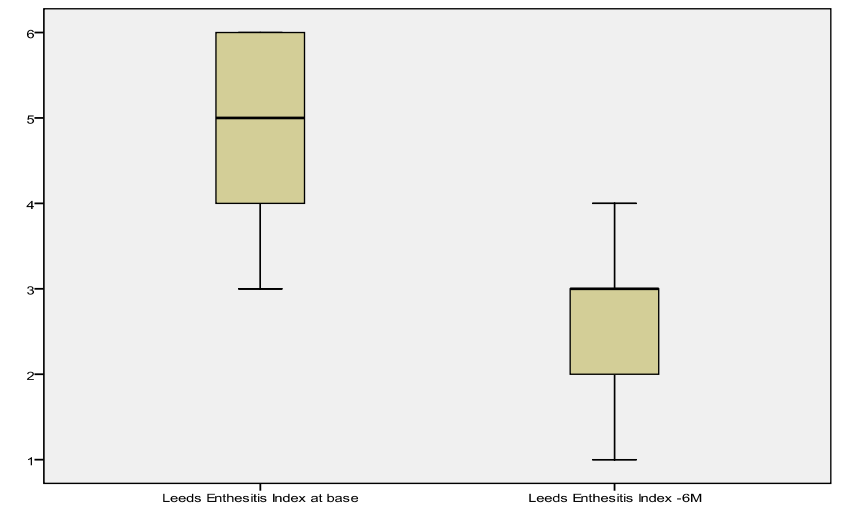

Figure 1: Box plots showing correlation of Leeds Enteritis Index score at baseline and after 6 months of treatment in patients with psoriatic arthritis. 


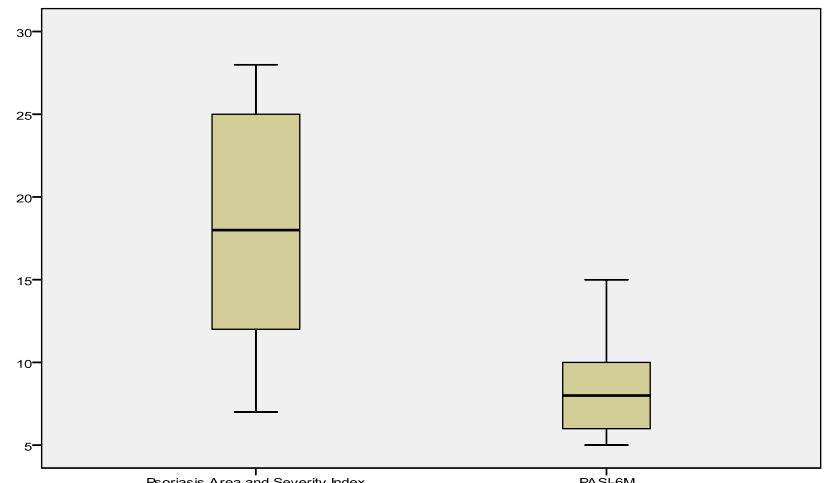

Figure 2: Box plots showing correlation of Psoriasis Area and Severity Index (PASI) score at baseline and after 6 months of treatment in patients with psoriatic arthritis.

In patients with PsA, PASI score was a direct highly significant correlation with LEI score $(r=0.538$, $\mathrm{p}<$ 0.001). Moreover, PASI score was a direct significant correlation with ESR ( $r=0.271, p<0.05)$, as well as PASI score was also a direct significant correlation with CRP $(r=0.269, p<0.05)$. However, PASI score was not significant correlation with age $(r$ $=0.144, p>0.05)$, disease duration $(r=0.091, p>0.05)$ or BMI ( $r=0.031, p>0.05)$.

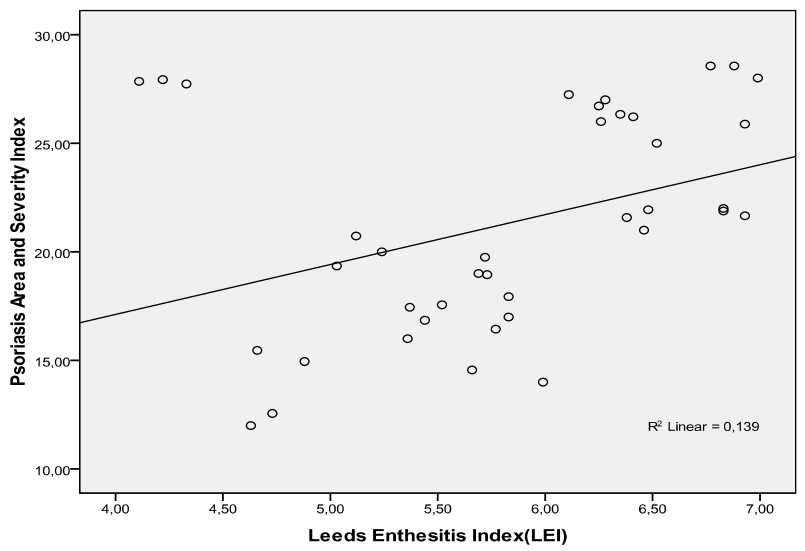

Figure 3: Linear regression correlation ( $r$-) of Psoriasis Area and Severity Index (PASI) score and Leeds Enteritis Index (LEI) score at baseline in patients with psoriatic arthritis.

\section{Discussion}

The prevalence of PSA among psoriatic patients ranges from $6 \%$ to $48 \%$, while the prevalence of psoriasis is $1-3 \%$ of the population [1618]. In current practice, our result showed that the most frequently clinical findings of PSA were enthesopathy (20.5\%), oligoarthritis (53.8\%), polyarthritis $(25.5 \%)$, spondylitis $(12.8 \%)$ and DIP involvement $(7.71 \%)$. Similar findings were reported by other authors. Naredo E et al. [19] demonstrated that ultrasound synovitis and enthesopathy were significantly more frequent in psoriatic patients than in controls. Ultrasound enthesopathy was present in $11.6 \%$ of entheses in the psoriasis group and $5.3 \%$ of entheses in the control group. Similarly, Yang Q [20] found that oligoarthritis $(48.2 \%)$ was the most common manifestation pattern, followed by enthesitis (26.8\%), spondylitis (26.8\%), polyarthritis (19.6\%) and classic DIP arthritis (5.4\%).

De Filippis et al. [21] also found that entheseal abnormalities present in six of 24 (25\%) patients with psoriasis who underwent ultrasonography but not detected at clinical examination. Furthermore, Kane D et al. [22] demonstrated that $40 \%$ of PSA had oligoarticular PsA; $60 \%$ had polyarticular PsA; $38 \%$ had peripheral enthesopathy; no patient had predominant spondylitis/sacroileitis; 37 (29\%) had dactylitis of digits; $12 \%$ had plantar fasciitis; $6 \%$ had Achilles tendonitis and $2 \%$ had tenosynovitis of the wrist. DIP involvement was present in $39 \%$ patients.

McGonagle D et al. [23] reported that enthesitis is considered an important feature of PsA. Enthesitis is common in PsA and considered important by affected patients [2]. Enthesitis has been indicated as a distinctive pathologic condition affecting patients with PSA [4]. Also, one of the major features of PsA is enthesitis [24]. Similarly, D'Agostino MA [25] reported that the commonest sites of involvement in PsA are Achilles tendon, patellar tendon, plantar fascia, and greater trochanter. The Achilles tendons are among the most frequent sites of enthesopathic involvement in PSA, producing soft-tissue inflammatory swelling, heel pain, and difficulty walking $[26,27]$.

This study disagrees with Reich $\mathrm{K}$ et al. [28] who reported that more than $95 \%$ of PsA patients had active arthritis and $53.0 \%$ had five or more joints affected. Polyarthritis (58.7 \%) was the most common manifestation pattern, followed by oligoarthritis (31.6 $\%)$, arthritis mutilans (4.9\%), distal interphalangeal involvement (41.0\%) and dactylitis (23.7\%). Also, In contrast to our results, Narváez J [29] found that the distinctive findings of enthesitis were present in nearly $71 \%$ of PsA patients in MRI results. However, Freeston $\mathrm{J}$ [30] found that $57.1 \%$ of the PsA group had clinical evidence of at least one tender enthesis.

A possible explanation of differences of prevalence of enthesitis between our results and results of other authors may be due methods of assessment of enthesitis such as clinical examination, ultrasonography or MRI.

In current practice, our results showed that the most frequently clinical findings of psoriasis were generalized plaque (56.4\%), localized plaque (28.2 $\%)$, guttate $(12.8 \%)$ and pustular lesion $(2.6 \%)$ in patients with PsA. In addition, mean ( \pm SD) of LEI score at baseline was $5.1( \pm 0.7)$ and mean ( \pm SD) of PASI score at baseline was $20.8( \pm 5.1)$ which means a severe psoriasis outcome at baseline in PsA. Similar findings were reported by other authors. Frediani B [31] demonstrated that PsA is associated with psoriatic lesions of the skin and/or nails, and 
serological tests for rheumatoid arthritis are negative. Yang Q et al. [20] compared patients with PsA and patients without PsA, patients with PsA had more severe skin disease (mean PASI 9.7 vs. 6.0), higher frequency of nail changes (46.4 \% vs. $21.0 \%$ ) and scalp involvement (90.2 \% vs. $76.4 \%)$. Also, Reich K et al. [28] compared patients with arthritis and patients without arthritis, patients with PsA had more severe skin symptoms (mean PASI 14.3 vs. 11.5). Girolomoni $G$ et al. [24] demonstrated that there was significantly higher baseline PASI score compared with the patients who had a good clinical outcome (14.5 vs. 3.8; $P<0.002)$.

Moreover, our results observed a significant decreased in LEI score, PASI score, ESR and CRP at baseline compared to results after 6 months of treatment in PSA. Similar findings were reported by other authors. Teoli $\mathrm{M}$ et al. [32] demonstrated that treatment with Adalimumab efficacy was associated reduction in disease activity indices, as DAS28, ESR, PASI, and SpA-HAQ particularly at week 12 . The PASI score at baseline of mean value of 9.2 showed improvement by mean of PASI score from 4.6 at 4 weeks to 1.8 at 12 weeks. Similarity, Mease PJ et al. [33] reported that biological agents, especially the antitumour necrosis factors, have demonstrated significant efficacy and reasonable safety in all clinical domains of PsA, resulting in amelioration of clinical symptoms, inhibition of structural damage and improvement of function and quality of life.

In the present study, PASI score was a direct highly significant correlation with LEI score, ESR and CRP. Girolomoni $G$ et al. [24] who reported that one of the major features of PSA is enthesitis and yet clinically asymptomatic cases of entheseal abnormalities are likely to go undiagnosed. Ultrasonography detected a significantly higher incidence of entheseal abnormalities in patients with psoriasis, despite the absence of clinical symptoms of arthropathy. Also, enthesitis may be associated with a more severe psoriasis outcome. Furthermore, McGonagle [34] reported that clinically unrecognized enthesitis (inflammation at tendon and ligament attachments) is commonly seen in early PsA at all sites of the disease. Specifically, enthesitis is associated with adjacent osteitis or bone and synovial inflammation. Moreover, Ash ZR et al. [35] demonstrated that enthesopathy scores were higher in patients with psoriatic nail disease than in patients without nail disease and healthy controls. In contrast to our results, Ash ZR et al. [35] showed that no link between the psoriasis area and severity index and enthesitis was evident. A possible Explanation of differences of correlation between enthesitis scores and severity of psoriasis from other authors may be due different methods of assessment of enthesopathy and severity of psoriasis as well as our patients had moderate-to-severe PsA.

Finally, mechanism of enthesitis in PsA may be explained by the extensive extracapsular inflammation. Half their patients showed extrasynovial inflammation including thickened ligaments and periarticular soft tissue [36]. MRI and US showed widespread juxtaarticular inflammation and inflammatory changes at sites of the juxtaarticular entheses [37]. Also, enthesitis may be explained degenerative lesions with or without microcalcification in PsA [37].

Enthesopathy showed a significant prevalence among PsA in Kuwait. The good potential activity parameters for PSA were Leeds Enteritis Index (LEI) Score, Psoriasis Area and Severity Index score (PASI), ESR and CRP. They may be a useful, a simple, safe, inexpensive, non-invasive methods for monitoring of disease activity in PsA. Also, they may be the predictive value of changes induced by biological treatment in PsA. Finally, this finding clearly requires evaluation in larger prospective clinical studies and further research are needed in the use of LEI score in other rheumatic diseases among Kuwaiti patients.

\section{Acknowledgments}

We would like to thank all the patients that participated in this study. We are grateful to our colleagues in the physical medicine and rehabilitation and dermatology departments for their assistance during this study and review of the manuscript.

\section{References}

1. Slobodin G, Rozenbaum M, Boulman N, Rosner I. Varied Presentations of Enthesopathy. Semin Arthritis Rheum. 2007;37(2):119-26 .

2. Kavanaugh A, Cassell S. The assessment of disease activity and outcomes in psoriatic arthritis. Clin Exp Rheumatol. 2005;23(5 Suppl 39):S142-7.

3. Gladman DD. Psoriatic arthritis from Wright's era until today. J Rheumatol Suppl. 2009;83:4-8.

4. McGonagle D, Conaghan P, Emery P. Psoriatic arthritis-a unified concept twenty years on. Arthritis Rheum. 1999;42(6):10806 .

5. McGonagle D, Stockwin L, Isaacs J, Emery P. An enthesitis based model for the pathogenesis of spondyloarthropathy. Additive effects of microbial adjuvant and biomechanical factors at disease sites. J Rheumatol. 2001;28:2155-9.

6. Healy PJ, Helliwell PS. Measuring clinical enthesitis in psoriatic arthritis: assessment of existing measures and development of an instrument specific to psoriatic arthritis.. Arthritis Rheum. 2008;59(5):686-91.

7. Vaz A, Barton J, Ritchlin C. Psoriatic arthritis: an update for clinicians. International Journal of Advances in Rheumatology. 2004; 2: 126-34.

8. Husted JA, Gladman DD, Farewell VT, Cook RJ. Health-related quality of life of patients with psoriatic arthritis: a comparison with patients with rheumatoid arthritis. Arthritis Rheum. 2001;45(2):1518.

9. Gladman DD, Farewell VT, Wong K, Husted J. Mortality studies in psoriatic arthritis; results from a single outpatient center. II. 
Prognostic indicators for death. Arthritis Rheum. 1998;41(6):110310.

10. Ashcroft DM, Wan Po AL, Williams HC, Griffiths CE. Clinical measures of disease severity and outcome in psoriasis: a critical appraisal of quality. Br J Dermatol. 1999;141(2):185-91.

11. Taylor WJ. Epidemiology of psoriatic arthritis. Curr Opin Rheumatol. 2002;14(2):98-103.

12. Hammer HB, Sveinsson M, Kongtorp AK, Kvien TK. A 78-joints ultrasonographic assessment is associated with clinical assessments and is highly responsive to improvement in a longitudinal study of patients with rheumatoid arthritis starting adalimumab treatment. Ann Rheum Dis. 2010;69(7):1349-51.

13. Westergren A. The technique of the red cell sedimentation reaction. American Review of Tuberculosis. 1926;14:94-100.

14. Clyne B, Olshaker JS. The C-reactive protein. J Emerg Med. 1999;17(6):1019-25.

15. Jonsson T, Arnason JA, Valdimarsson H. Enzyme-linked immunosorbent assay (ELISA) screening test for detection of rheumatoid factor. Rheumatol Int. 1986;6(5):199-204

16 .Koo J. Population-based epidemiologic study of psoriasis with emphasis on quality of life assessment. Dermato Clin. 1996;14(3):485-96.

17. Shbeeb M, Uramoto KM, Gibson LE, O'Fallon WM, Gabriel SE. The epidemiology of psoriatic arthritis in Olmsted County, Minnesota, USA, 1982-1991. J Rheumatol. 2000;27(5):1247-50.

18. Alenius GM, Stenberg B, Stenlund H, Lundblad M, Dahlqvist SR. Inflammatory joint manifestations are prevalent in psoriasis: prevalence study of joint and axial involvement in psoriatic patients, and evaluation of a psoriatic and arthritic questionnaire. $J$ Rheumatol. 2002;29(12):2577-82.

19. Naredo E, Möller I, de Miguel E, Batlle-Gualda E, Acebes C, Brito E, Mayordomo L, Moragues C, Uson J, de Agustín JJ, Martínez A, Rejón E, Rodriguez A, Daudén E. High prevalence of ultrasonographic synovitis and enthesopathy in patients with psoriasis without psoriatic arthritis: a prospective case-control study. Rheumatology (Oxford). 2011;50(10):1838-48.

20. Yang Q, Qu L, Tian H, Hu Y, Peng J, Yu X, Yu C, Pei Z, Wang $G$, Shi $B$, Zhang $F$, Zhang $Y$, Zhang $F$. Prevalence and characteristics of psoriatic arthritis in Chinese patients with psoriasis. J Eur Acad Dermatol Venereol. 2011;25(12):1409-14

21. De Filippis LG, Caliri A, Lo Gullo R, Bartolone S, Micel G, Cannavò SP, Borgia F, Basile G, Aloisi G, Zimbaro G, Scribano $E$, Bagnato GF. Ultrasonography in the early diagnosis of psoriasis-associated enthesopathy. Int J Tissue React. 2005;27(4):159-62.

22. Kane D, Stafford L, Bresnihan B, FitzGerald O. A prospective, clinical and radiological study of early psoriatic arthritis: an early synovitis clinic experience. Rheumatology (Oxford). 2003;42(12):1460-8.

23. McGonagle D, Gibbon W, Emery P. Classification of inflammatory arthritis by enthesitis. Lancet. 1998;352(9134):113740.

24. Girolomoni G, Gisondi P. Psoriasis and systemic inflammation: underdiagnosed enthesopathy. J Eur Acad Dermatol Venereol. 2009;23(Suppl 1):3-8.

25. D'Agostino MA, Said-Nahal R, Hacquard-Bouder C, Brasseur $\mathrm{JL}$, Dougados M, Breban M. Assessment of peripheral enthesitis in the spondylarthropathies by ultrasonography combined with power Doppler: a cross-sectional study. Arthritis Rheum. 2003; 48(2):52333.

26. Galluzzo E, Lischi DM, Taglione E, Lombardini F, Pasero G, Perri G, Riente L. Sonographic analysis of the ankle in patients with psoriatic arthritis. Scand J Rheumatol. 2000;29(1):52-5.
27. Lehtinene A, Taavitsainen M, Leirisalo-Repo M. Sonographic analysis of enthesopathy in the lower extremities of patients with spondyloarthropathy. Clin Exp Rheumatol. 1994;12(2):143-8.

28. Reich K, Krüger K, Mössner R, Augustin M. Epidemiology and clinical pattern of psoriatic arthritis in Germany: a prospective interdisciplinary epidemiological study of 1511 patients with plaquetype psoriasis. Br J Dermatol. 2009;160(5):1040-7.

29. Narváez J, Narváez JA, de Albert M, Gómez-Vaquero C, Nolla JM. Can Magnetic Resonance Imaging of the Hand and Wrist Differentiate Between Rheumatoid Arthritis and Psoriatic Arthritis in the Early Stages of the Disease? Semin Arthritis Rheum. 2012;42(3):234-45.

30. Freeston J, Coates L, Helliwell P, Hensor E, Wakefield $R$, Emery $\mathrm{P}$, Conaghan $\mathrm{P}$. Is there sub-clinical enthesitis in early psoriatic arthritis? A clinical comparison with power Doppler ultrasound. Arthritis Care Res (Hoboken). 2012;64(10):1617-21.

31. Frediani B, Falsetti P, Storri L, Allegri A, Bisogno S, Bald $F$, Marcolongo R. Ultrasound and clinical evaluation of quadricipital tendon enthesitis in patients with psoriasic arthritis and rheumatoid arthritis. Clin Rheumatol. 2002;21(4):294-8.

32. Teoli $M$, Zangrilli $A$, Chimenti MS, Talamonti $M$, Bavetta $M$, Graceffa D, Perricone R, Chimenti S. Evaluation of clinical and ultrasonographic parameters in psoriatic arthritis patients treated with adalimumab: a retrospective study. Clin Dev Immunol. 2012;2012:823854.

33. Mease PJ. Psoriatic arthritis: update on pathophysiology, assessment and management. Ann Rheum Dis. 2011;70(Supp 1):i77-84.

34. McGonagle D. Enthesitis: an autoinflammatory lesion linking nail and joint involvement in psoriatic disease. J Eur Acad Dermatol Venereol. 2009;23(Suppl 1):9-13.

35. Ash ZR, Tinazzi I, Gallego CC, Kwok C, Wilson C, Goodfield M, Gisondi P, Tan AL, Marzo-Ortega H, Emery P, Wakefield RJ, McGonagle DG, Aydin SZ. Psoriasis patients with nail disease have a greater magnitude of underlying systemic subclinical enthesopathy than those with normal nails. Ann Rheum Dis. 2012;71(4):553-6

36. Jevtic V, Watt I, Rozman B, Kos-Golja M, Demsar F, Jarh O. Distinctive radiological features of small hand joints in rheumatoid arthritis and seronegative spondyloarthritis demonstrated by contrast-enhanced (Gd-DTPA) magnetic resonance imaging. Skeletal Radiol. 1995;24(5):351-5.

37. Coates LC, Anderson RR, Fitzgerald O, Gottlieb AB, Kelly SG, Lubrano E, McGonagle DG, Olivieri I, Ritchlin CT, Tan AL, De Vlam K, Helliwell PS..Clues to the Pathogenesis of Psoriasis and Psoriatic Arthritis from Imaging: A Literature Review. J Rheumatol. 2008;35(7):1438-42.

38. De Simone C, Guerriero C, Giampetruzzi AR, Costantini M, Di Gregorio F, Amerio P.. Achilles tendinitis in psoriasis: Clinical and sonographic findings. J Am Acad Dermatol. 2003;49(2):217-22. 